\title{
Atrial and ventricular pacing after open heart surgery
}

\author{
J. D. WISHEART ${ }^{1}$, J.E.C. WRIGHT ${ }^{2}, F . L . R O S E N F E L T^{3}$, \\ and J.K. ROSS \\ National Heart Hospital, London W.1
}

\begin{abstract}
The effect of cardiac pacing, through a wide range of pacing rates, has been studied in 13 patients in stable sinus rhythm within 24 hours of operation. Using first atrial and then ventricular pacing, the cardiac rate was raised to $60 \%$ above control value. The effects of atrial and ventricular pacing were compared by observing the differences in the various parameters measured at corresponding paced heart rates. With atrial pacing there was no significant difference in the cardiac output, mean aortic pressure, mean left atrial pressure, or left ventricular work. During ventricular pacing there were significant falls in cardiac output $(P<0.05)$, mean aortic pressure $(P<0.01)$, and left ventricular work $(P<0.01)$. There was a significant rise in mean left atrial pressure $(\mathrm{P}<0.01)$.

In this study atrial pacing had no significant effect on the parameters measured, through a wide range of cardiac rates. An inotropic effect resulting from increase of rate was not seen. Reported increases in cardiac output following pacing must therefore have resulted from correction of a dysrhythmia. Ventricular pacing incurs a definite haemodynamic penalty if used in patients with an intact atrioventricular conducting pathway. If atrial pacing is not available, this penalty must be balanced against the possible haemodynamic advantage of suppressing a dysrhythmia.
\end{abstract}

Harris et al. (1967) demonstrated the value of rate augmentation by cardiac pacing in the management of bradycardias and certain dysrhythmias following open heart surgery in man. By capturing the cardiac rhythm, pacing may increase the rate, suppress the dysrhythmia, and increase the cardiac output (Litwak et al., 1968; Frieson et al., 1968; Woodson, Frieson, and Starr, 1968; Nathan, Mundth, Buckley, and Austen, 1969). This haemodynamic improvement may be due either to the correction of the abnormal rhythm (Harris et al., 1967; Nathan et al., 1969) or to an intrinsic inotropic effect consequent upon increasing the heart rate (Covell et al., 1967; Sarnoff and Mitchell, 1961; Mitchell, Wallace, and Skinner, 1963; Litwak et al., 1968; Sonnenblick, Morrow, and Williams, 1966; Stein et al., 1966). This study was designed to test the latter possibility by measuring the effects of augmenting the rate by atrial pacing in stable postoperative patients with sinus rhythm.

Frieson et al. (1968) and Woodson et al. (1968) have demonstrated that for a given paced rate atrial pacing had more beneficial haemodynamic

1Present address: Department of Surgery, University of Alabama in Birmingham, Alabama 35233, U.S.A.

2Present address: The London Chest Hospital

3Present address: Department of Surgery, Duke University, North

Carolina, U.S.A.

Reprints from J. E. C. Wrigh effects than ventricular pacing, in patients with sinus rhythm, in whom the atrioventricular conduction pathway was intact. The second object of these studies was to observe whether this difference occurred throughout a range of paced rates.

\section{METHODS}

Thirteen patients, 12 male and one female, whose ages ranged from 23 to 54 years, have been investigated. Aortic valve replacement with either a homograft (Ross, 1968) or a fascia lata valve (Ionescu et al., 1970) had been carried out. The condition of the patients was clinically stable; they were in sinus rhythm and the investigation was done within 24 hours of operation.

The techniques of measurement and the parameters measured are schematically represented in Figure 1.

CARDIAC OUTPUT Cardiac output was measured by the dye dilution technique (Balcon and Sowton, 1969 ; Bennet, Balcon, Hoy, and Sowton, 1970) using indocyanine green, which was injected into the right atrium through the central venous pressure catheter. Arterial blood was sampled from the radial artery (occasionally the femoral artery), passed through a cuvette, and analysed by a Gilford densitometer. After amplification the dye dilution curve was inscribed by a direct writing Honeywell recorder, and, 


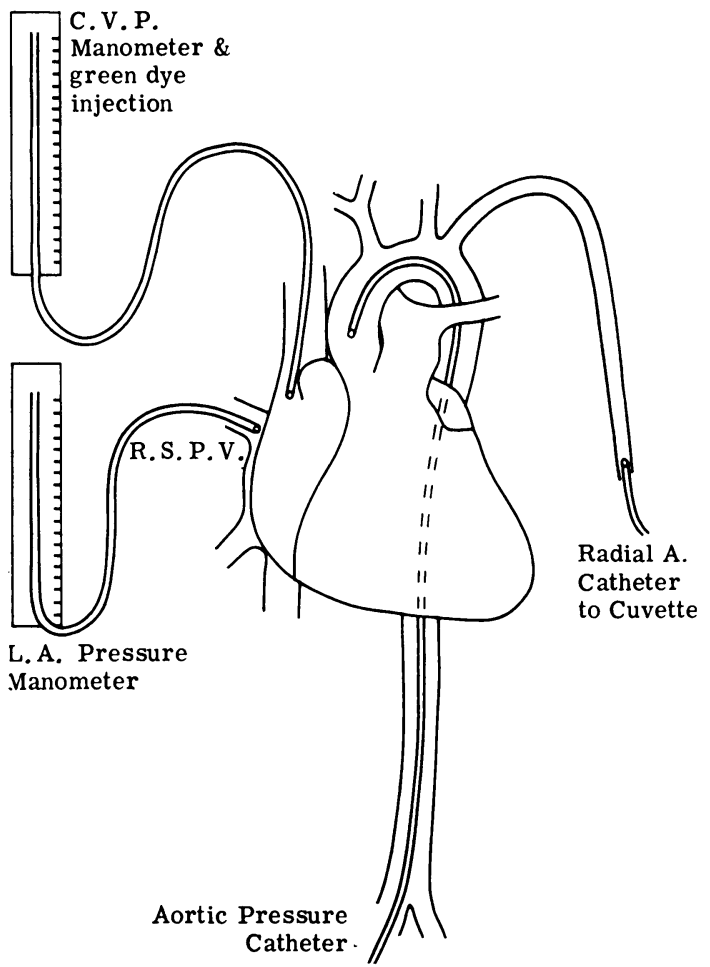

FIG. 1. Schematic representation of parameters measured. $C V P=$ central venous pressure; $R S P V=$ right superior pulmonary vein; $L A=$ left atrium.

after the area under this curve had been measured by planimetry, the cardiac output was calculated using standard formulae. A mean of two recordings was taken. After the dye curves had been inscribed, the blood was re-infused into the patient's arterial system.

ARTERIAL BLOOD PRESSURE After cannulation of the femoral artery percutaneously with a fine catheter, using a Riley needle, the pressure in the proximal aorta was monitored.

LEFT ATRIAL PRESSURE The pressure in the left atrium was monitored using a polythene intravenous catheter inserted at operation into the left atrium through the right superior pulmonary vein, using a double purse string of $4 / 0$ Mersilene. Both the aortic and left atrial catheters were attached to transducers and the pressures were recorded on a multi-channel recorder (Devices).

ELECTROCARDIOGRAM The electrocardiogram was continuously monitored.

Pacing Pacing was carried out through unipolar electrodes attached at operation to the epicardium of the right atrium and the right ventricle: the indifferent electrode was in the subcutaneous tissue.
Demand pacing using a Devices Box (Type 'E' Seriad No. 2990) was used with independent control rate and the stimulus voltage. The rate will be described as a percentage rise above control valu (Balcon and Sowton, 1969) rather than in absoluf figures.

The derived parameters were obtained as follows: Systolic ejection rate Systolic ejection rate $(\mathrm{ml} / \mathrm{s}) \stackrel{\equiv}{\equiv}$ stroke volume $(\mathrm{ml})$ systolic ejection time (s)

The stroke volume is obtained with knowledge of the cardiac output and the heart rate. The systolf ejection time is known from examination of the dynamic aortic pressure tracings (Sarnoff and Bergo lund, 1954). Systolic ejection rate is widely accepteg as an index of the rate of fibre shortening of the myocardium (Balcon and Sowton, 1969 ; Levine et at 1962) but some believe this is not so (Ross, Linhart and Braunwald, 1965 ; Hamer, 1968 ; Dexter et a产 1951).

Left ventricular work $\mathrm{LVW}=\mathrm{CO} \times \mathrm{K}(\mathrm{MAP}-\mathrm{LAR}$ where $\mathrm{LVW}=$ left ventricular work $(\mathrm{kgm} / \mathrm{min}) ; \mathrm{C} \Theta^{\prime}$ $=$ cardiac output $(1 . / \mathrm{min}) ; \mathrm{K}=$ constant $; \mathrm{MAP} \Xi$ mean aortic pressure $(\mathrm{mmHg})$; and $\mathrm{LAP}=$ mean le atrial pressure $(\mathrm{mmHg})$. Thus a change in the value of LVW is a composite reflection of changes i cardiac output, mean aortic pressure, and mean le atrial pressure.

The investigation of each patient followed the sam $\vec{E}$ pattern (Fig. 2). A series of control observations was made and atrial pacing was then begun. The resting rate had usually been between $85 / \mathrm{min}$ and $95 / \mathrm{mi}$. and the rhythm could be captured by atrial pacing with a rise in rate of less than $12.5 \%$. The maximun rate was about $140 / \mathrm{min}$ in each case, representing a rise of up to $60 \%$. Observations were also made at a paced rate in between these two. In each case 8 minimum of 15 minutes was allowed for stabilization in the altered circumstances (Litwak et al., 1968 After further control readings ventricular pacing was begun and observations were made at similar rateg A final set of control measurements was made.

\section{PLAN OF EACH STUDY}

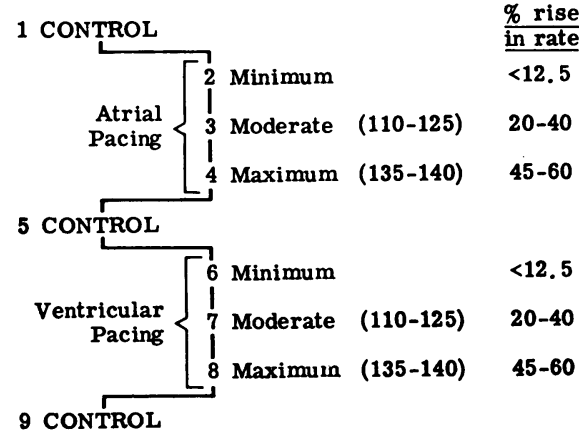

FIG. 2. Plan of each study (see text). 


\section{ANALYSIS}

To evaluate the haemodynamic effect of rate increase alone for each parameter measured, the results obtained at each rate during atrial pacing were compared with the control values. The effects of atrial and ventricular pacing were compared by observing the differences in the various parameters at corresponding paced heart rates. In order to demonstrate the underlying stability of the heart the control values measured before and after each type of pacing were also compared. All these differences were analysed using the paired $t$ test and standard probability tables.

\section{RESULTS}

CONTROL VALUES The control observations for each parameter showed no significant change between measurements before and after pacing (Figs. 3 to 7).

MEAN AORTIC PRESSURE (Fig. 3) Atrial pacing resulted in a small rise in mean aortic pressure of up to $6 \mathrm{mmHg}$, which was not statistically significant. Ventricular pacing caused a significant fall of up to $9.7 \mathrm{mmHg}(\mathrm{P}<0.01)$. When ventricular pacing was discontinued the mean aortic pressure immediately returned to the higher control values. When the values obtained at corresponding rates during atrial and ventricular pacing were compared, the differences at the moderate and maximum rates were significant and were $13.1 \mathrm{mmHg}$ $(P<0.01)$ and $10.1 \mathrm{mmHg}(\mathrm{P}<0.05)$ respectively. The greatest difference was $7 \%$ of the control mean aortic pressure. At the minimum rate there was no significant difference either from the control values or between atrial and ventricular pacing.

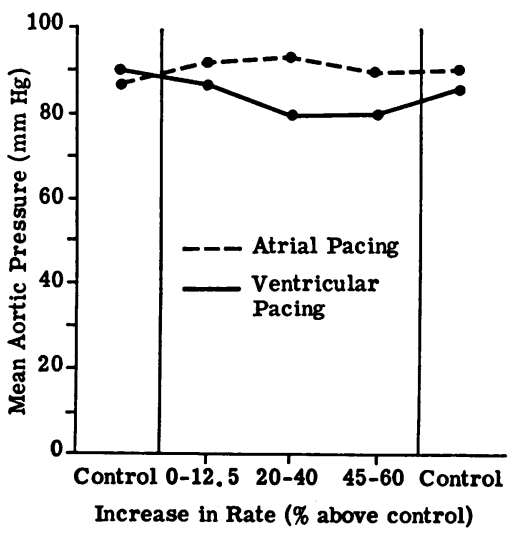

FIG. 3. Effect of pacing on mean aortic blood pressure (9 patients).

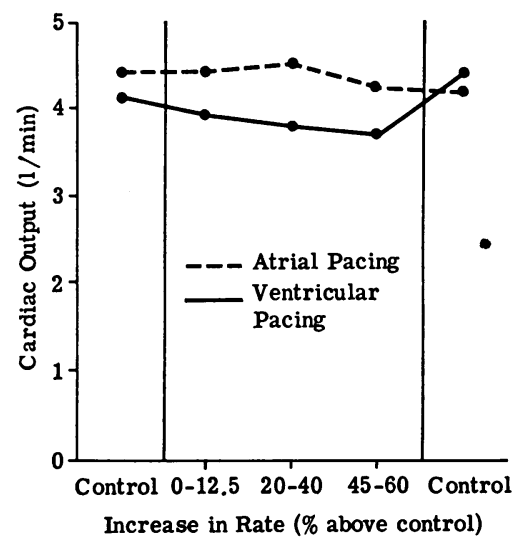

FIG. 4. Effect of pacing on cardiac output (mean of 11 patients).

CARDIAC OUTPUT (Fig. 4) There was no significant change in cardiac output during atrial pacing. During ventricular pacing there was a fall in cardiac output which reached significance $(P<0.05)$ at the maximum rate; there was immediate recovery to the control value when ventricular pacing was withdrawn. When the values obtained at corresponding rates during atrial and ventricular pacing were compared, the differences at minimum, moderate, and maximum rates were all significant and were $0.481 / \mathrm{min}(P<0.05), 0.70$ $1 / \mathrm{min}(\mathrm{P}<0.05)$, and $0.561 / \mathrm{min}(\mathrm{P}<0.01)$ respectively. The greatest difference was $15 \%$ of the control cardiac output.

LEFT ATRIAL PRESSURE (Fig. 5) During atrial pacing there was no significant change in mean

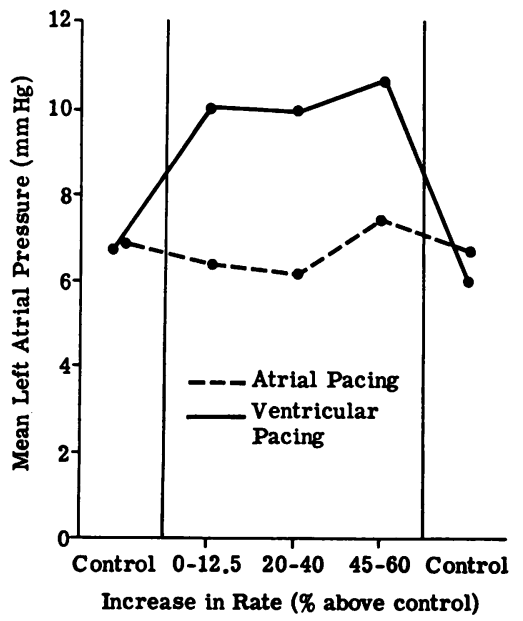

FIG. 5. Effect of pacing on mean left atrial pressure (9 patients). 
left atrial pressure. Ventricular pacing caused significant elevation of the mean left atrial pressure at all rates. When the effects of atrial and ventricular pacing at corresponding rates were compared, there were significant differences of $3.73(\mathrm{P}<0.01), 3.85(\mathrm{P}<0.01)$, and $3.27(\mathrm{P}<0.001)$ $\mathrm{mmHg}$ at the minimum, moderate, and maximum rates. These differences were up to $50 \%$ of the control pressure.

LEFT VENTRICULAR WORK (Fig. 6) Atrial pacing caused no significant change in left ventricular work. Ventricular pacing caused significant falls at moderate and maximum paced rates. The difference between the effects of atrial and ventricular pacing was significant at each rate: $0.96 \mathrm{kgm} / \mathrm{min}$ $(\mathbf{P}<0.5), 2.17 \mathrm{kgm} / \mathrm{min}(\mathrm{P}<0.01)$, and $1.40 \mathrm{kgm} /$ min $(\mathrm{P}<0.001)$ at minimum, moderate, and maximum rates respectively. These differences were up to $38 \%$ of the control value.

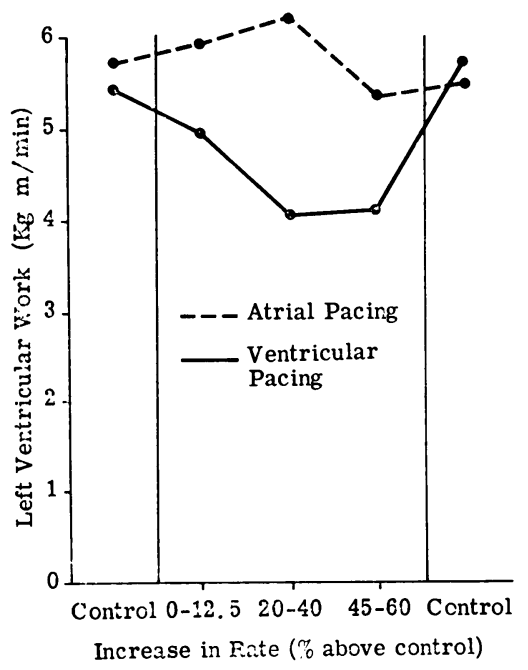

FIG. 6. Effect of pacing on left ventricular work (7 patients).

SYSTOLIC EJECTION RATE (Fig. 7) Atrial pacing caused a fall in systolic ejection rate which became significant $(P<0.05)$ at the maximum rate only. Ventricular pacing caused a fall of $37 \mathrm{ml} / \mathrm{s}$ $(P<0.01)$ at the moderate rate and $55 \mathrm{ml} / \mathrm{s}$ $(P<0.01)$ at the maximum rate. The differences between the effects of atrial and ventricular pacing were small and reached statistical significance only at the maximum rate $(P<0.05)$ with a difference of $16 \mathrm{ml} / \mathrm{s}$.

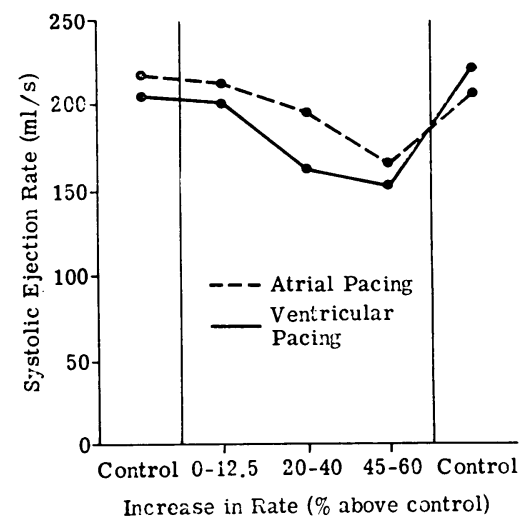

FIG. 7. Effect of pacing on systolic ejection rate $(7 \vec{c}$ patients).

\section{DISCUSSION}

Bradycardia occurring after open heart surgery. may lead to reduced cardiac output and predispose-0 to dysrhythmias (Harris et al., 1967; Litwak et al., 1968; Nathan et al., 1969): dysrhythmias will likewise cause a fall in cardiac output and may lead: to potentially fatal ventricular dysrhythmias.. (Litwak et al., 1968; Hoffman et al., 1969). When $\overrightarrow{\vec{O}^{7}}$ there is a cause such as hypoxia, hypokalaemia, 3 altered acid-base status, digoxin intoxication, or inadequate coronary perfusion (Harris et al.,? 1967; Litwak et al., 1968; Hoffman et al., 1969), therapy should be directed towards its correction.을 When there is no identifiable cause empirical $x$ therapy may be used, either with a pharma-o cological agent such as procainamide (Friedberg, 1966; Leading article, British Medical Journal, 응 1970a) or lignocaine (Friedberg, 1966; Binnion, Murtagh, Pollock, and Fletcher, 1969), or with a은 physical agent such as pacing (Harris et al., 1967). By capturing the cardiac rhythm, pacing may suppress the dysrhythmia, augment the rate, andN increase the cardiac output (Harris et al., 1967; Litwak et al., 1968). Frieson et al. (1968) and Woodson et al. (1968) recorded rises of up to $20-\tilde{W}$ $30 \%$ in cardiac output using atrial pacing. When nodal rhythm was captured by atrial pacing ao rise of up to $60 \%$ was found (Frieson et al., 1968)

CAUSE OF IMPROVED HAEMODYNAMICS There are two possible causes for this haemodynamic im $\frac{P}{\mathbb{D}}$ provement. Correction of the abnormal rhythm? and restoration of more efficient cardiac action may be responsible (Harris et al., 1967) or there may be an intrinsic inotropic effect consequents upon increasing the heart rate. The theoreticat 
basis for the latter possibility is found in the work of Sarnoff and Mitchell (1961) and other reports. They have shown that an increase in rate causes an increase in ventricular contractility in both animals (Sarnoff and Mitchell, 1961; Covell et al., 1967; Mitchell et al., 1963) and in normal men (Stein et al., 1966; Benchimol and Ligget, 1966), as indicated by a rise in tension-time index or a fall in left ventricular end-diastolic pressure. Similar findings are reported by Balcon and Sowton (1969) who increased the rate by atrial pacing in patients with ischaemic heart disease. However, the increased myocardial contractility observed by these authors was not accompanied by an improvement in performance, as judged by such haemodynamic criteria as, for example, the cardiac output.

In our study the principal criteria were cardiac output, left atrial pressure, aortic pressure, and left ventricular work. During atrial pacing we found these parameters to remain essentially stable with increasing rate, as did Sarnoff and Mitchell (1961), Stein et al. (1966), and Balcon and Sowton (1969). It is possible that with more refined techniques, such as measurement of acceleration in the ascending aorta, a change in contractility could be detected. However, it is difficult to imagine how a change, so small that it is not reflected in the haemodynamic criteria that we measured, could be of much practical value. This study therefore suggests that the improved haemodynamic status which occurs when atrial pacing is used to control dysrhythmias is due to correction of the rhythm and restoration of efficient cardiac action and not to any inotropic effect of rate augmentation.

COMPARISON OF ATRIAL AND VENTRICULAR PACING In patients in whom the atrioventricular conduction pathways are intact, pacing may be achieved by either atrial or ventricular stimulation. Many studies have been carried out comparing the results of the two methods in different circumstances. Mitchell, Gilmore, and Sarnoff (1962) and Gilmore, Sarnoff, Mitchell, and Linden (1963), in carefully controlled experiments in dogs, demonstrated that ventricular function was significantly depressed by ventricular pacing, as compared with atrial pacing. Benchimol, Ellis, and Dimond (1965) studied normal human subjects and were unable to demonstrate any significant difference in the haemodynamic parameters, except that there was a greater fall in systolic ejection rate with ventricular pacing. In patients with heart disease, both Benchimol et al. (1965) and Samet, Bernstein, Levine, and Lopez (1965) showed that cardiac performance was more efficient with atrial pacing. Previous studies with bradycardias and dysrhythmias following open heart surgery have shown that with a modest rise in rate to a level not exceeding $115-120 / \mathrm{min}$ atrial pacing may achieve a rise in cardiac output of up to $30 \%$, while ventricular pacing in the same circumstances may cause a fall in cardiac output of $10-20 \%$ (Frieson et al., 1968; Woodson et al., 1968). In the present studies the subject did not have a dysrhythmia and with atrial pacing the cardiac output was not increased, but with ventricular pacing it fell by $17 \%$. Whereas in the previous studies these observations were made at one paced rate only, this report shows that these effects may be observed at different rates up to $140 / \mathrm{min}$, and the difference becomes more marked at higher heart rates. This pattern was seen consistently in all the haemodynamic parameters observed. It should be stressed that with atrial pacing there is no haemodynamic penalty in increasing the rate to $140 / \mathrm{min}$. This is consistent with the findings of Balcon and Sowton (1969), Benchimol and Ligget (1966), Ross et al. (1965), and Wright, Fabian, and Epstein (1970), but Kloster et al. (1966) and Benchimol et al. (1965) state that in patients with heart failure the optimum rate lies between 110 and $120 / \mathrm{min}$.

REASONS FOR DIFFERENCE The reasons for this difference have been a recurring subject for discussion in recent years. The atrium functions as a reservoir whether atrial systole occurs or not. Synchronized atrial systole, however, enables the atrium to function as a supplemental pump, achieving a left ventricular end-diastolic pressure which is greater than the mean left atrial pressure; this is important with regard to the enddiastolic state of myocardial fibres and ventricular contractility, and also to the retrograde effect of mean left atrial pressure on pulmonary venous circulation (Braunwald, 1964). Atrial contraction is also considered to contribute to efficient closure of the atrioventricular valves (Braunwald, 1964; Leading article, British Medical Journal, 1970b), and in ventricular pacing large ' $v$ ' waves occur in the left atrial pressure recordings, suggesting some mitral insufficiency (Gilmore et al., 1963; Mitchell et al., 1962; Samet et al., 1965). Finally, where excitation occurs via normal pathways a coordinated ventricular contraction results, while if excitation is initiated at an ectopic site where a ventricular electrode is implanted, the resultant contraction is not coordinated (Gilmore et al., 1963). The healthy heart is assumed to have sufficient reserves of function to compensate for these 
factors when ventricular pacing is carried out in normal subjects (Leading article, British Medical Journal, 1970b).

We wish to thank Dr. R. Balcon for his advice in planning this work, Miss J. Woods for technical assistance, Dr. J. Chamberlain for help with the statistical analysis, Miss R. Craddock for drawing the figures, and Mrs. B. Westbrook for typing the manuscript.

\section{REFERENCES}

Balcon, R. B., and Sowton, E. (1969). The haemodynamic effects of atrial pacing in patient with ischaemic heart disease. Acta med. scand., 188, 119.

Benchimol, A., Ellis, J. G., and Dimond, E. G. (1965). Hemodynamic consequences of atrial and ventricular pacing in patients with normal and abnormal hearts. Amer. J. Med., 39, 911.

ing stimulation of the right atrium, right ventricle and left ventricle in normal and abnormal hearts. Circulation, 33, 933.

Bennet, D., Balcon, R., Hoy, J., and Sowton, E. (1970). Haemodynamic effects of dextro-propranolol in acute myocardial infarction. Thorax, 25, 86.

Binnion, P. F., Murtagh, G., Pollock, A. M., and Fletcher, E. (1969). Relation between plasma lignocaine levels and induced haemodynamic changes. Brit. med. J., 3, 390.

Braunwald, E. (1964). The hemodynamic significance of atrial systole. Amer. J. Med., 37, 665 .

Covell, J. W., Ross, J. Jr., Taylor, R., Sonnenblick, E. H., and Braunwald, E. (1967). Effects of increasing frequency of contraction on the force velocity relation of the left ventricle. Cardiovasc. Res., 1, 2.

Dexter, L., Whittenberger, J. W., Haynes, F. W., Goodale, W. T., Gorlin, R., and Sawyer, C. G. (1951). Effect of exercise on circulatory dynamics of normal individuals. J. appl. Physiol., 3, 439.

Friedberg, C. K. (1966). Diseases of the Heart, 3rd ed. W. B. Saunders, Philadelphia and London.

Frieson, W. G., Woodson, D. R., Ames, A. W., Herr, R. H., Starr, A., and Kassebaum, D. G. (1968). A hemodynamic comparison of atrial and ventricular pacing in postoperative cardiac surgical patients. $J$. thorac. cardiovasc. Surg., 55, 271.

Gilmore, J. P., Sarnoff, S. J., Mitchell, J. H., and Linden, R. J. (1963). Synchronicity of ventricular contraction: observations comparing haemodynamic effects of atrial and ventricular pacing. Brit. Heart J., 25, 299.

Hamer, J. (1968). Cardiac work and contractility. Brit. Heart J., 30, 443.

Harris, P. D., Malm, J. R., Bowman, F. O., Kaiser, G., and Singer, D. H. (1967). Epicardial pacing to control arrhythmias following cardiac surgery. Circulation, 36, Suppl. II, p. 133.
Hoffman, S. A., Wallace, H. W., Baue, A. E., Blakemorę W. S., and Zinsser, H. F. (1969). Postoperative ventric 등 ular arrhythmias caused by isoproterenol. J. thorac cardiovasc. Surg., 58, 664.

Ionescu, M. I., Ross, D. N., Deac, R., Grimshaw, V. A.尺 Taylor, S. H., Whitaker, W., and Wooler, G. A. (1970)ल्లు Autologous fascia lata for heart valve replacement. Thorax, 25, 46.

Kloster, F. E., Bristow, J. D., Starr, A., McCord, C. W., and Griswold, H. E. (1966). Serial cardiac output and bloow volume studies following cardiac valve replacement? Circulation, 33, 528.

Leading article (1970a). Prophylaxis of dysrhythmias afteri myocardial infarction. Brit. med. J., 1, 646. (1970b). Atrial function in man. Brit. med. J., 1, 189.

Levine, H. J., Neill, W. A., Wagman, R. J., Krasnow, N.옹 and Gorlin, R. (1962). The effect of exercise on mean left ventricular ejection rate in man. J. clin. Invest., $41-$ 1050 .

Litwak, R. S., Kuhn, L. A., Gadboys, H. L., Lukban, S. B.ב and Sakurai, H. (1968). Support of myocardial per formance after open cardiac operations by rate augmentation. J. thorac. cardiovasc. Surg., 56, 484.

Mitchell, J. H., Gilmore, J. P., and Sarnoff, S. J. (1962) Transport function of the atrium. Amer. J. Cardiol.; 9, 237.

—_, Wallace, A. G., and Skinner, N. S. Jr. (1963). Intrinsios effects of heart rate on left ventricular performance $\bar{\partial}$ Amer. J. Physiol., 205, 41.

Nathan, M. J., Mundth, E. D., Buckley, M. J., and Austen W. G. (1969). A new method for the placement of epicardial atrial pacing electrodes. J. thorac. cardiovasc $\overrightarrow{\bar{\nabla}}$ Surg., 58, 145.

Ross, D. N. (1968). Homograft replacement of the aortic valve. Surgery, 63, 382.

Ross, J. Jr., Linhart, J. W., and Braunwald, E. (1965) Effects of changing the heart rate in man by electrica stimulation of the right atrium. Circulation, 32, 549.

Samet, P., Bernstein, W. H., Levine, S., and Lopez, A (1965). Hemodynamic effects of tachycardias producedo by atrial and ventricular pacing. Amer.J. Med., 39, 905

Sarnoff, S. J., and Berglund, E. (1954). Ventricular function. Circulation, 9, 706.

- and Mitchell, J. H. (1961). The regulation of the performance of the heart. Amer. J. Med., 30, 747.

Sonnenblick, E. H., Morrow, A. G., and Williams J. FD (1966). The effects of heart rate on the dynamics of force development in the intact human ventricle. Circulation, $\mathrm{N}$
3, 945 .

Stein, E., Damato, A. N., Kosowsky, B. D., Lau, S. H., andN Lister, J. W. (1966). Relation of heart rate to cardio-N vascular dynamics. Circulation, 33, 925.

Woodson, R. D., Frieson, W. G., and Starr, A. (1968) Use of atrial pacing in cardiac surgical patients. Amero J. Cardiol., 21, 120.

Wright, J. S., Fabian, J., and Epstein, E. J. (1970). Immediate effect on cardiac output of reversion to sinus rhythm from rapid arrhythmias. Brit. med. J., 3, 315 . 